Original Article

\title{
Internet addiction among the undergraduate students
}

\author{
C. Rajeswari ${ }^{1}$, Ramachandra ${ }^{2}$, Nimishamol Joseph ${ }^{3}$, Nivya George ${ }^{4}$, Pavithra k $^{5}$, \\ Penini Syhly ${ }^{6}$, Prinu Jose ${ }^{7}$ \\ ${ }^{1}$ Lecturer, ${ }^{2}$ Professor, ${ }^{3,4,5,6,7}$ undergraduate students, college of nursing, NIM HANS, Hosur road, Bangalore - 29. \\ *Corresponding Author : C. Rajeswari, Lecturer, College of Nursing, NIM HANS, Hosur Road, Bangalore-29, \\ Mobile : +919980874360, E-mail : rajic2007@ rediffmail.com
}

$\begin{array}{ll}\text { Received } & : 18.06 .2016 \\ \text { Review Completed } & : 13.12 .2016 \\ \text { Accepted } & : 01.01 .2017\end{array}$

Keywords : Internet, addiction, undergraduate students.

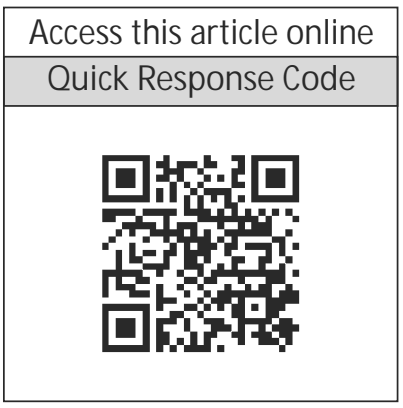

\begin{abstract}
Background : Internet addiction is an alarming issue which has significant impact on the lifestyle of people. Younger generation need to use internet judiciously and productively to prevent the underlying risks ahead.
\end{abstract}

Aim: To assess the degree of internet addiction among undergraduate students.

Methods : Using a non-experimental descriptive cross sectional research design, internet addiction was assessed among 200 undergraduate students studying at selected colleges in Bangalore city using Internet Addiction Scale.

Results : Forty nine percent (98) of the undergraduate students had mild addiction, $28.5 \%$ (57) were moderately addicted, and $0.5 \%$ (1) was severely addicted. No addiction was identified in $22 \%(44)$.

Degree of internet addiction was significantly associated with gender, course of study, level of education, religion, educational status of parents, total number of children in the family and internet use of significant others.

Conclusion : Though the intensity of addiction varies, majority of the undergraduate students studied were addicted to internet. Awareness about this addictive behaviour and timely intervention can protect this productive group of the society from the harmful effect of this internet addiction.

\section{Introduction}

Internet has a revolutionary impact on the day to day life of every individual. The number of internet users worldwide has increased 10 folds from 1993-2013. The first billion was reached in 2005, the second in 2010 and the third billion in 2014. In 2014 the percentage of internet users worldwide was $40.4 \%$ and in India $19.9 \%$ of total population. ${ }^{1}$

Excessive internet use may be determined by using track of time, neglecting basic drives such as hunger and sleep, withdrawal system and negative behaviour including anger, fatigue and social isolation. Kimberly S. Young (1995) defined internet addiction as the compulsive urge to continually use the net, whether it be to spend hours surfing the web, hang around in chat rooms or play online games. $^{2}$

Internet addiction has its effect in all dimensions of health.
Easy and quick access to internet and negligence towards this issue makes young adults more susceptible to addiction which eventually results in personal, social and educational difficulties especially in students. A descriptive study designed to ascertain the extent of internet addiction in 100 randomly selected public school children in age group of 16-18years using Davis online cognition scale found that addictive use of internet was associated with significant social, psychological and occupational impairment. Dependents were found to delay other work to spend time online, lose sleep due to late night log on, and feel life would be boring without the internet. ${ }^{3} \mathrm{~A}$ descriptive comparative study conducted to estimate the impact of internet addiction among 150 college students in Alborz province, Iran concluded that there was a significant inverse relationship between internet addiction and studentsmental health. ${ }^{4}$ 
Undergraduates students are considered to be on high risk for internet addiction because of varied reasons such as their blocks of unstructured time, provision of free and unlimited access to the internet at schools and universities, first time being away from the parental control, lack of monitoring, problems of adapting to college life, finding companionship by using internet, skills to use different applications etc. $^{5}$

In spite of the fact that the internet contributes positively in many ways, reduction in individual productivity and other harmful effects makes internet addiction a vital issue to be attended immediately. Investigating its intensity among youth helps to intervene effectively to protect them from the threats of impaired academic performance, physical, psychological and social wellbeing.

Working with under graduate students and often witnessing their uncontrolled use of mobile phones and computers lead the investigators to investigate the internet addiction among this group as an initial step to find solution for safe use of this growing technology.

\section{Materials and methods}

An institution based descriptive cross sectional study was conducted to assess the degree of internet addiction among the undergraduate students studying at selected colleges of Bangalore city. Educational institutions were selected purposively, based on the criteria of course offered, proximity and availability of permission. Using non probability convenient sampling technique, 200 undergraduates from different disciplines like, Medicine (39), Engineering (28), Nursing (50), Business management (37), and Commerce(46) and consented to participate in the study were considered as study participants.

Socio-demographic characters assessed include age, gender, course of study, educational level, religion, place of stay, type of family, monthly income of the family, educational status of parents, number of children in family, birth order, source of information on internet addiction, hours spent in internet usage and use of internet by significant others and its duration. Internet Addiction was assessed by a five point scale develo ped by Kimberly Young (1994) which is a reliable and widely used tool to assess the addictive use of internet. This scale consist of 20 items with the scores ranging from 0-5 and interpreted as does not apply, rarely, occasionally, frequently, often and always respectively. The total score ranges from $0-100$ which is categorized into 0-19 score -no addiction, 20-49 - mild addiction, 50-79 - moderate addiction and 80-100 score severe addiction.

Formal permission was obtained from the institutional authorities and written consent was taken from individual subject explaining the nature and purpose of the study.Data was collected by administering the tool individually. Confidentiality and anonymity were maintained throughout.

\section{Results}

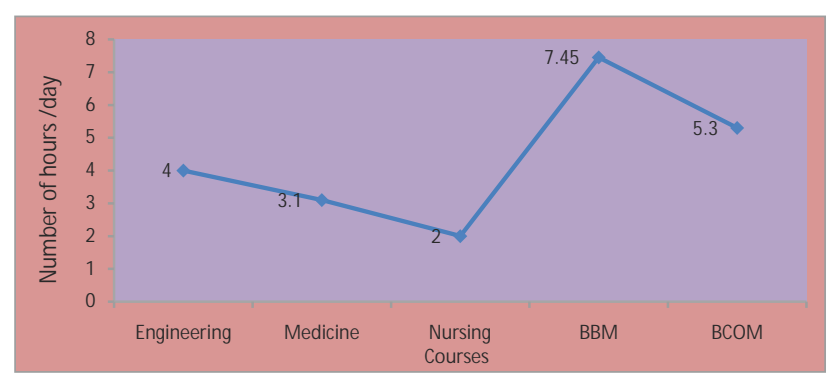

Fig 1 : Average hours spent in internet usage by undergraduate students of various courses.

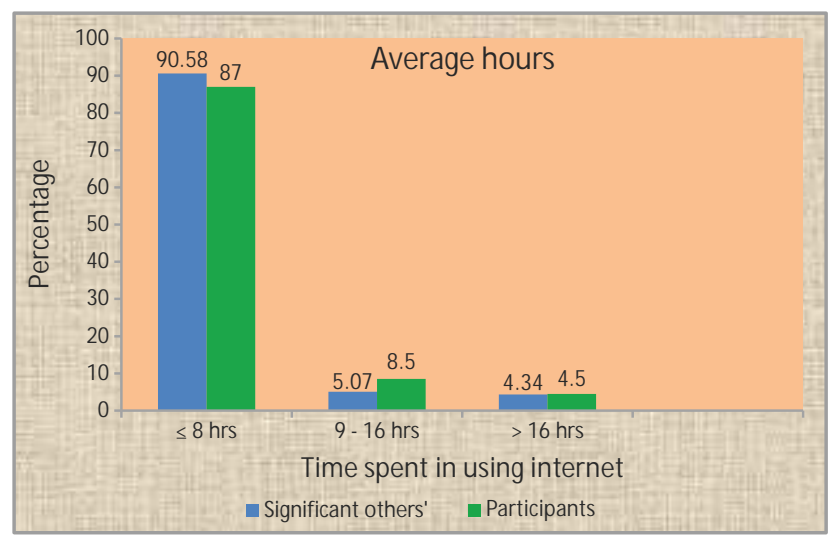

Fig 2 : Comparison of duration of internet usage by participants' and significant others. 
Table 1: Degrees of internet addiction among undergraduate students

$\mathrm{N}=200$

\begin{tabular}{|c|l|c|c|c|c|c|c|c|c|}
\hline SI & \multirow{2}{*}{ nourse } & \multicolumn{2}{|c|}{ No addiction } & \multicolumn{2}{c|}{ Mild } & \multicolumn{2}{c|}{ Moderate } & \multicolumn{2}{|c|}{ Severe } \\
\cline { 2 - 11 } & & $\mathbf{f}$ & $\%$ & $\mathbf{f}$ & $\mathbf{\%}$ & $\mathbf{f}$ & $\mathbf{\%}$ & $\mathbf{f}$ & $\%$ \\
\hline 1 & BBM & 1 & 2.7 & 20 & 54.05 & 15 & 40.54 & 1 & 2.7 \\
\hline 2 & B.Com & 9 & 19.56 & 23 & 50 & 14 & 30.43 & 0 & 0 \\
\hline 3 & Nursing & 21 & 42 & 28 & 56 & 1 & 2 & 0 & 0 \\
\hline 4 & M edical & 7 & 17.95 & 18 & 46.15 & 14 & 35.89 & 0 & 0 \\
\hline 5 & Engineering & 6 & 21.43 & 9 & 32.14 & 13 & 46.43 & 0 & 0 \\
\hline & OVERAL & $\mathbf{4 4}$ & $\mathbf{2 2}$ & $\mathbf{9 8}$ & $\mathbf{4 9}$ & $\mathbf{5 7}$ & $\mathbf{2 8 . 5}$ & $\mathbf{1}$ & $\mathbf{0 . 5}$ \\
\hline
\end{tabular}

\section{Discussion}

The mean age of the subjects was 19.81 and Rs.68, 001 was the mean monthly income of the family. $60 \%$ (120) of the subjects were females. $25 \%$ (50) of the participants were nursing students, 23\% (46) were B.Com graduates, 19.5\% (39) belongs to Medicine, $18.5 \%$ (37) were BBM students and $14 \%$ (28) were engineering graduates. $34.5 \%$ (69) of the students were in first year, $22.5 \%$ (45), 14\% (28) and $29 \%(58)$ were in second, third and fourth year respectively. At the time of data collection, $52.5 \%$ (105) were residing at home, $41.5 \%$ (83) were in hostels and 6\% (12) were staying in Paying Guest accommodation. 79.5\% (159) were from nuclear family and rest were from an extended family. Majority of the participant's parents have completed either secondary education or graduation. $62.5 \%$ (125) were from a family with 2 children where as $86.5 \%$ (173) were either first or second child of the family.

Analysis showed that average hours spent in internet usage per day (fig1) was maximum in BBM students which was 7.45 hours, followed by B.Com students 5.3 hours, Engineering students 4 hours, Medical students 3.1 hours and Nursing students which was 2 hours. All subjects were aware about internet addiction of which 48.5\% (97) had information through friends and peers $47.5 \%$ (95) through mass media and $4 \%$ (8) by parents and relatives.69\% (138) had at least one significant member in the family or room also using internet out of which $50.7 \%$ (70) of them were siblings, $18.1 \%$ (25) were parents and $31.2 \%$ (43) were roommates.

The average time spent in internet usage by the study subjects and the significant others were almost similar (fig2). Less than 8 or equal hrs of internet usage was reported by $87 \%$ of the subjects and $90.58 \%$ significant others. $9-16$ hrs was reported by $8.5 \%$ in the study subjects and $5.07 \%$ in the significant others. More than 16 hrs was reported by 4.5 and 4.34 respectively.

Degree of internet addiction assessed among undergraduate students (Table 1 ) showed that $22 \%$ (44) of them were not addicted to internet, $49 \%$ (98) were mildly addicted, $28.5 \%$ (57) were moderately addicted, and 0.5\% (1) Similar results found in a study conducted by were severely addicted to internet. Mild addiction was more in nursing students which was $56 \%$ (28). Whereas moderate addiction was high among Engineering students which was $46.43 \%$ (13) and severe addiction was found to be high in BBM students $2.7 \%$ (1).NajmiHayati Usman et al (2013) conducted a study to assess internet addiction using Young's internet addiction test among 120 foreign undergraduate students in University of Technology, Malaysia and found that $25.8 \%$ (31) had mild addiction, $69.2 \%(83)$ were moderately addicted and $5 \%(6)$ were severely addicted to internet ${ }^{6}$.

Degree of internet addiction was significantly associated with gender, course of study, level of education, religion, educational status of parents, total number of children in the family and internet use of significant others. Academic burden, higher educational status of parents and their use of internet at home, loneliness resulting from modern single child family could be the possible reasons for addiction. Influence of siblings who are already exposed to internet can indeed contribute to the internet addiction. The wide range of possibilities and life style modifications create and continue to create new adductors of modern era.

Dai-Pai-Feng,sue-Huei Chang (2009), conducted a study to assess internet addiction using Chen Internet Addiction Scale among 209 junior high school students showed that there was a higher percentage of internet addiction among male students than females and there was no difference in internet addiction to the educational background of parents, living conditions and place where internet was used. $^{7}$ 


\section{Conclusion}

Though the intensity of addiction varies, majority of the undergraduate students studied were addicted to internet.

Awareness about this addictive behaviour and timely

\section{References}

1. http:// www.internetlivestats.com/internet-users/

2. http://www.spike magazine.com/0698caug.php

3. KanwalNalwa, Archana PreetAnand. Internet addiction in students: A cause of concern. Cyber psychology and behavior 2003 November; 6(6):653-656.

4. RamezanJahanian, ZeinabSeifury. The impact of internet addiction on students' mental health in technical and vocational colleges in Alborz Province.M iddle-East journal of scientific research 2013;14(11):15331538.

5. Takeshi Sato. Internet addiction among students: prevalence and psychological problems in Japan. JM AJ 2006 july-August;49:279-283.

6. NajmiHayati Usman, Masoumeh Alavi, Syed Mohamed Shafeq. Relationship between internet addiction and academic performance among foreign undergraduate students. Procedia social and behavioral science 2014;114:845-851.

7. Dai-Pai Feng, Su-Huei Chang. A study on the internet addiction problems of junior high school students in Taipei. 2009:1-20. intervention can protect this productive group of the society from the harmful effect of this internet addiction. 